To me they all seemed to be blowing the same way. Many years ago they caused me to formulate the hypothesis $I$ have restated above, and all the further knowledge $I$ have gleaned seems to me to suggest that we have here a method of general application which may point the way to as signal a victory over the viruses as has been achieved in other fields by the sulphonamides and penicillin. Even in bacterial infections it is a great adjuvant to their action; for viruses it seems at present our only practicable method.

I should not close this letter without a note about the administration of "dekadexolin." For some reason it does not act well unless it is given into the gluteal muscles, and more than $1 \mathrm{ml}$. should not be given in one spot if pain is to be avoided and absorption hastened. Absorption is probably the great problem and not at all a simple matter. One might see even more marked effects if larger doses could be given intravenously as a very fine emulsion. The production of emulsions of the requisite fineness and stability presents great technical difficulties, though I have handled them, and if the general thesis of this letter is correct they would no doubt be made generally available. There may be other substances more effective than vitamins A and D. "Dekadexolin" anyhow is perfectly harmless, for I have given full doses to newborn babies as well as to the very aged. I only hope that this letter may stimulate research into the physicochemical effects of vitamins as well as their catalytic actions, for it may well add to our control over illness and improve the health of our patients. - I am, etc.,

Winsford, Cheshire.

W. N. LEAK.

\section{Calcification of the Thyroid Gland}

SIR,-I read Dr. R. T. Shiggins's report (Dec. 14, 1946, p. 899) of calcification of the thyroid gland with interest. A few days later I saw a somewhat similar case which you may consider worthy of record.

\section{CASE Report}

An unmarried female patient aged 62 years was admitted to hospital complaining of frequent vomiting for 9 weeks prior to admission. She had had an operation for carcinoma of the right breast eleven years previously. Examination revealed a moderately wasted individual of neurotic temperament. There was a hard fixed mass attached to the mid-sternum and clinical signs suggesting metastatic carcinoma of lungs and mediastinum; abdomen, N.A.D.

Radiography confirmed the presence of widespread secondary deposits in sternum, lungs, and mediastinum, and showed an oval calcified mass measuring $5.0 \mathrm{~cm}$. long, $3.0 \mathrm{~cm}$. broad, and $2.5 \mathrm{~cm}$. antero-posteriorly situated in the position of the left lobe of the thyroid gland.

Clinically the neck was normal on inspection, but palpation revealed a hard movable oval mass in the region occupied by the left thyroid lobe, which moved freely on swallowing. The patient showed no signs of abnormal thyroid activity or of local pressure.

In these circumstances, and having regard to her general condition, exploration was not indicated. The differential diagnosis would appear to include calcified lymph gland, calcified adenoma of thyroid, and calcification of the left lobe of the thyroid. In view of the standard measurements of a thyroid lobe $-5 \mathrm{~cm}$. by $3 \mathrm{~cm}$. by $2 \mathrm{~cm}$. (Gray's Anatomy, 27th edition)-calcification of the lobe would seem the most probable. It is interesting to note that digestive symptoms were prominent in both patients, and, in each, abdominal investigation was negative.-I am, etc.,

South Shields, Co. Durham.

R. T. Towson.

\section{R.M.B.F. Christmas Gift Fund}

SIR,-I would like to thank through your Journal all who have generously subscribed to our Christmas Gifts Fund; it is a very great pleasure to be able to report that over $£ 2,200$ has been received.

On behalf of the Committee I warmly thank all the contributors and at the same time would like to express our gratitude to all the British Medical Association Divisions and Branches, Panel Committees, and Medical Societies who arranged collections or who gave donations.-I am, etc.,

\section{Luther Batteson,} Hon. Treasurer Royal Medical Benevolent Fund.

\section{Obituary}

\section{SIR ARNOLD LAWSON, K.B.E., F.R.C.S.}

Sir Arnold Lawson, for many years ophthalmic surgeon to Middlesex Hospital, and afterwards a member of its consulting staff, died on Jan. 19 at the age of 79. He was an exceptionally able ophthalmologist and a man of attractive personality. $\mathrm{He}$ was born in London in 1867, the son of George Lawson, F.R.C.S., surgeon-oculist to Queen Victoria. One of the tasks he undertook early in his professional career was to revise and largely rewrite in 1903 the sixth edition of his father's notable textbook Diseases and Injuries of the Eye.

He went to Merchant Taylors' School, and then began his training at the Middlesex Hospital, where he was Senior Entrance Scholar. His school career gave promise of future high achievement. He won the Hetley clinical prize in 1890 , and later he became Senior Broderip Scholar. He qualified in 1891 , and in the same year took the M.D. of the University of Brussels. In 1893 he became a Fellow of the Royal College of Surgeons. Paternal example, no doubt, determined his choice of ophthalmology, and he had the great advantage of a period as clinical assistant to Sir John Tweedy at Moorfields. He joined his father in consulting

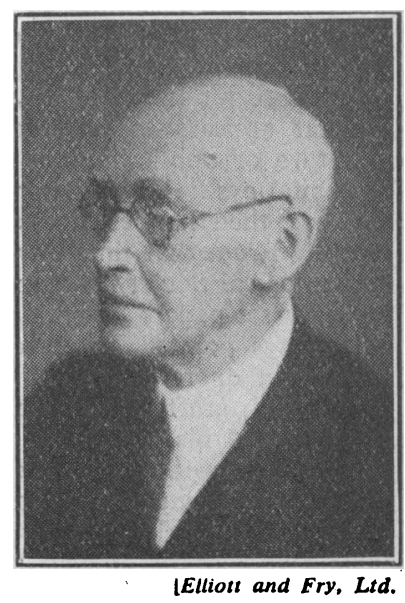
practice at No. 12, Harley Street, and continued at that address after his father's death and throughout his professional life. In 1896 he was appointed ophthalmic surgeon to the Paddington Green Children's Hospital, a position which he held until 1910 , when he became assistant ophthalmic surgeon to his old hospital, the Middlesex, and full ophthalmic surgeon and lecturer on ophthalmology four years later. These posts he retained until his retirement under the age limit, when he was elected to the consulting staff. From 1900 to 1914 he was also surgeon to the Royal London Ophthalmic Hospital, and here again he was afterwards consulting surgeon. Other institutions with which he was assuciated as a consultant were the Royal Victoria Hospital and Home for Incurables, Putney, and Epsom College.

When St. Dunstan's for War-blinded Soldiers, Sailors, and Airmen was founded by the late Sir Arthur Pearson during the first world war, Lawson discovered there a form of service which engaged all his sympathy as well as his clinical skill. He served the institution not only as ophthalmic surgeon but as chairman of the Ophthalmic Advisory Board. His experiences among blinded soldiers were set out in a narrative, War Blindness at St. Dunstan's, published in 1922. He also served other war institutions, including the King Edward VII Hospital for Officers. In 1939 he was appointed part-time civil consultant (ophthalmic) to the Royal Navy.

Sir Arnold Lawson took a conspicuous share in the advancement of ophthalmology in general. He stood aside from the semi-political aspects of ophthalmic service, but he did a great deal to advance the subject on its scientific and clinical side. He was a prominent figure for nearly half a century in the Ophthalmological Society of the United Kingdom, of which his father was an original member. For very many years Sir Arnold served as its treasurer with scrupulous care. The Society had his real affection, and it was due to him and the late Treacher Collins and some others that it kept its identity and refrained from amalgamation in the Royal Society of Medicine. But he was an active member of the R.S.M. and at one time president of its Ophthalmological Section. He also served as one of the honorary officers of the Section of Ophthalmology at Annual Meetings of the British Medical Association in 1899, 1906, and 1927. At the meeting in Edinburgh in 